Abstract

\title{
Tungsten Oxide Based Hydrogen Gas Sensor Prepared by Advanced Magnetron Sputtering ${ }^{\dagger}$
}

\author{
Nirmal Kumar*(D), Stanislav Haviar *(D), Jiř́i Rezek, Jiři Čapek and Pavel Baroch \\ Department of Physics and NTIS-European Centre of Excellence, University of West Bohemia, Univerzitni 8, \\ 30100 Pilsen, Czech Republic; jrezek@ntis.zcu.cz (J.R.); jcapek@kfy.zcu.cz (J.Č.); pbaroch@kfy.zcu.cz (P.B.) \\ * Correspondence: kumarn@kfy.zcu.cz (N.K.); haviar@ntis.zcu.cz (S.H.) \\ + Presented at the 8th International Symposium on Sensor Science, 17-28 May 2021; Available online: \\ https://i3s2021dresden.sciforum.net/.
}

check for updates

Citation: Kumar, N.; Haviar, S.; Rezek, J.; Čapek, J.; Baroch, P. Tungsten Oxide Based Hydrogen Gas Sensor Prepared by Advanced Magnetron Sputtering. Eng. Proc. 2021, 6, 5. https://doi.org/ 10.3390/I3S2021Dresden-10154

Academic Editors: Gianaurelio Cuniberti and Larysa Baraban

Published: 18 May 2021

Publisher's Note: MDPI stays neutral with regard to jurisdictional claims in published maps and institutional affiliations.

Copyright: (C) 2021 by the authors. Licensee MDPI, Basel, Switzerland. This article is an open access article distributed under the terms and conditions of the Creative Commons Attribution (CC BY) license (https:// creativecommons.org/licenses/by/ $4.0 /)$.

\begin{abstract}
In this study, we demonstrate the advantages of two advanced sputtering techniques for the preparation of a thin-film conductometric gas sensor. We combined tungsten oxide $\left(\mathrm{WO}_{3}\right)$ thin films with other materials to achieve enhanced sensorial behavior towards hydrogen. Thin films of $\mathrm{WO}_{3}$ were prepared using the DC and HiPIMS technique, which allowed us to tune the phase composition and crystallinity of the oxide by changing the deposition parameters. The second material was then added on-top of these films. We used the copper tungstate $\mathrm{CuWO}_{4}$ in the form of nano-islands deposited by reactive rf sputtering and Pd particles formed during conventional dc sputtering. The specimens were tested for their response to a time-varied hydrogen concentration in synthetic air at various temperatures. The sensitivity and response time were evaluated. The performance of the individual films is presented as well as the details of the synthesis. Advanced magnetron techniques (such as HiPIMS) allowed us to tune the property of the film to improve its sensorial behavior. The method is compatible with the silicon electronics industry and consists of a few steps that do not require any wet technique, and the films can be used in an as-deposited state. Therefore, sensorial nanostructured materials prepared using magnetron sputtering are very suitable for use in miniaturized electronic devices.
\end{abstract}

Keywords: hydrogen sensor; copper tungstate; tungsten oxide; magnetron sputtering; nanostructures; HiPIMS

Supplementary Materials: The presentation file is available at https:/ /www.mdpi.com/article/10.3 390/I3S2021Dresden-10154/s1. 